\title{
Tunneling across SAMs Containing Oligophenyl Groups
}

\section{Citation}

Bowers, Carleen M., Dmitrij Rappoport, Mostafa Baghbanzadeh, Felice C. Simeone, KungChing Liao, Sergey N. Semenov, Tomasz Żaba, Piotr Cyganik, Alan Aspuru-Guzik, and George M. Whitesides. 2016. Tunneling Across SAMs Containing Oligophenyl Groups. The Journal of Physical Chemistry C 120, no. 21: 11331-11337. doi:10.1021/acs.jpcc.6b01253. http:// dx.doi.org/10.1021/acs.jpcc.6b01253.

\section{Published Version}

10.1021/acs.jpcc.6b01253

\section{Permanent link}

http://nrs.harvard.edu/urn-3:HUL.InstRepos:29950635

\section{Terms of Use}

This article was downloaded from Harvard University's DASH repository, and is made available under the terms and conditions applicable to Open Access Policy Articles, as set forth at http:// nrs.harvard.edu/urn-3:HUL.InstRepos:dash.current.terms-of-use\#OAP

\section{Share Your Story}

The Harvard community has made this article openly available.

Please share how this access benefits you. Submit a story.

Accessibility 


\section{Tunneling across SAMs Containing Oligophenyl}

\section{Groups}

Carleen M. Bowers, ${ }^{a}$ Dmitrij Rappoport, ${ }^{a}$ Mostafa Baghbanzadeh, ${ }^{a}$ Felice C. Simeone, ${ }^{a}$ Kung-

Ching Liao, ${ }^{a}$ Sergey N. Semenov, ${ }^{a}$ Tomasz Żaba, ${ }^{b}$ Piotr Cyganik, ${ }^{b}$ Alan Aspuru-Guzik, ${ }^{a}$ and

George M. Whitesides ${ }^{a, c *}$

${ }^{a}$ Department of Chemistry and Chemical Biology, Harvard University, 12 Oxford Street, MA

02138

${ }^{b}$ Smoluchowksi Institue of Physics, Jagiellonian University, ul. Lojasiewicza 11, 30-348 Krakow,

Poland

${ }^{c}$ Kavli Institute for Bionano Science \& Technology, School of Engineering and Applied Sciences, Harvard University, 29 Oxford Street, MA 02138

* Author to whom correspondence should be addressed. 


\section{ABSTRACT}

This paper describes rates of charge tunneling across self-assembled monolayers (SAMs) of compounds containing oligophenyl groups, supported on gold and silver, using $\mathrm{Ga}_{2} \mathrm{O}_{3} / \mathrm{EGaIn}$ as the top electrode. It compares the injection current, $J_{0}$, and the attenuation constant, $\beta$, of the simplified Simmons equation, across oligophenyl groups $\left(\mathrm{R}=\mathrm{Ph}_{\mathrm{n}} ; \mathrm{n}=1,2,3\right)$, with three different anchoring groups (thiol, $\mathrm{HSR}$; methanethiol, $\mathrm{HSCH}_{2} \mathrm{R}$; and acetylene, $\mathrm{HC} \equiv \mathrm{CR}$ ) that attach $\mathrm{R}$ to the template-stripped gold and silver substrates. The results demonstrate that the structure of the molecules between the anchoring group (-S- or $-\mathrm{C} \equiv \mathrm{C}-$ ) and the oligophenyl moiety significantly influences charge transport. $\mathrm{SAMs}$ of $\mathrm{SPh}_{\mathrm{n}}$, and $\mathrm{C} \equiv \mathrm{CPh}_{\mathrm{n}}$ on gold show similar values of $\beta$ and $\log \left|J_{0}\right|\left(\beta=0.28 \pm 0.03 \AA^{-1}\right.$ and $\log \left|J_{0}\right|=2.7 \pm 0.1$ for $\mathrm{Au} / \mathrm{SPh}_{\mathrm{n}} ; \beta=0.30 \pm$ $0.02 \AA^{-1}$ and $\log \left|J_{0}\right|=3.0 \pm 0.1$ for $\left.\mathrm{Au} / \mathrm{C} \equiv \mathrm{CPh}_{\mathrm{n}}\right)$. The introduction of a single intervening methylene $\left(\mathrm{CH}_{2}\right)$ group, between the anchoring sulfur atom and the aromatic units to generate SAMs of $\mathrm{SCH}_{2} \mathrm{Ph}_{n}$, increases $\beta$ to $\sim 0.6 \AA^{-1}$ on both gold and silver substrates. (For $n$ alkanethiolates on gold the corresponding values are $\beta=0.76 \AA^{-1}$ and $\left.\log \left|J_{0}\right|=4.2\right)$. As a generalization, based on this and other work, it seems that increasing the height of the tunneling barrier in the region of the interfaces increases $\beta$, and may decrease $J_{0}$; by contrast, it appears that lowering the height of the barrier at these interfaces has little influence on $\beta$ or $J_{0}$.

KEYWORDS: Charge transport, EGaIn, molecular electronics, alkynes, self-assembled monolayer 


\section{INTRODUCTION}

The correlation between the structure of self-assembled monolayers (SAMs) containing $n$-alkyl groups and rates of charge tunneling in junctions of the form $\mathrm{M} / \mathrm{A}\left(\mathrm{CH}_{2}\right)_{\mathrm{n}} \mathrm{T} / / \mathrm{Ga}_{2} \mathrm{O}_{3} / \mathrm{EGaIn}(\mathrm{M}=$ the metal substrate, $\mathrm{A}$ is the anchoring group, and $\mathrm{T}$ is the terminal group) is surprisingly straightforward: the length of the insulating - $\left(\mathrm{CH}_{2}\right)_{\mathrm{n}}$ - groups, which present high tunneling barriers, largely controls the rate of charge transport. The height and shape of this tunneling barrier make the influence of many structural changes at the interfaces (i.e. changes to the anchoring group, A, and the terminal group, T) difficult to detect. ${ }^{1}$ Among the exceptions are the observation of a small "odd-even effect" in charge transport across $n$-alkanethiolates on gold, ${ }^{2-4}$ the observation of a substantial reduction in current density when fluorine is present at the $\mathrm{SAM} / / \mathrm{Ga}_{2} \mathrm{O}_{3}$ interface, ${ }^{5}$ and the observation of rectification of current when $\mathrm{T}$ is a redox active group such as ferrocenyl ${ }^{6-8}$ or bipyridyl. ${ }^{9}$

Having studied the influence of the structure of saturated $n$-alkyl groups on charge tunneling extensively, ${ }^{10-15}$ we turned our attention to understanding the relationship between the structure of polyaromatics (molecules that result in a reduction in the height of the tunneling barrier relative to that characterizing aliphatics ${ }^{16}$ ) and the rates of charge transport. We measured rates of charge transport across SAMs of oligophenylthiols $\left(\mathrm{M} / \mathrm{SPh}_{\mathrm{n}}\right)$, -methanethiols $\left(\mathrm{M} / \mathrm{SCH}_{2} \mathrm{Ph}_{\mathrm{n}}\right)$, and -acetylenes $\left(\mathrm{M} / \mathrm{C} \equiv \mathrm{CPh}_{\mathrm{n}}\right)$, where $\mathrm{n}=1-3$ and $\mathrm{M}=$ gold and silver metal electrodes (Figure 1). Using junctions of the form $\mathrm{M} / \mathrm{A}(\mathrm{Ph})_{\mathrm{n}} \mathrm{T} / / \mathrm{Ga}_{2} \mathrm{O}_{3} / \mathrm{EGaIn}$, we compared these rates with rates for length-matched $n$-alkanethiols. Although these SAMs are based on simple oligophenyls and share (we assume) a similar $\mathrm{Ph}-\mathrm{H} / / \mathrm{Ga}_{2} \mathrm{O}_{3}$ interface, they differ substantially in their physical and electronic interactions with the metal substrates that form the "bottom" electrodes. Our results indicate that $\mathrm{SAMs}$ of $\mathrm{SPh}_{n}$ and $\mathrm{C} \equiv \mathrm{CPh}_{\mathrm{n}}$ on gold, which are characterized 
by orbital overlap (conjugation) across the molecule, and between the molecule and the electrode ${ }^{17}$ have similar, low values of the attenuation factor $\beta$ in the simplified Simmons equation $^{18}$ (eq. 1) and the injection current, $J_{0}\left(\beta=0.28 \pm 0.03 \AA^{-1}\right.$ and $\log \left|J_{0}\right|=2.7 \pm 0.1$ for $\mathrm{Au} / \mathrm{SPh}_{\mathrm{n}} ; \beta=0.30 \pm 0.02 \AA^{-1}$ and $\log \left|J_{0}\right|=3.0 \pm 0.1$ for $\left.\mathrm{Au} / \mathrm{C} \equiv \mathrm{CPh}_{\mathrm{n}}\right)$.

$$
J(V)=J_{0}(V) e^{-\beta d}=J_{0}(V) 10^{-\frac{\beta d}{2.303}}
$$

The introduction of a single intervening $\mathrm{CH}_{2}$ group into the $\mathrm{S}-\mathrm{C}$ bond converts $\mathrm{SPh}_{\mathrm{n}}$ to $\mathrm{SCH}_{2} \mathrm{Ph}_{\mathrm{n}}-$ a group that disrupts the delocalization of orbitals between the aromatic moiety and the metal electrode $\mathrm{e}^{19-21}$ —and increases $\beta$ to $0.66 \pm 0.06 \AA^{-1}$ and $\log \left|J_{0}\right|$ to $4.0 \pm 0.3$; these values are similar to those derived from SAMs of $n$-alkanethiols $\left(\beta_{\mathrm{Au}}=0.76 \pm 0.03 \AA^{-1}\right.$ and $\log \left|J_{0}\right|=4.2$ $\pm 0.2)^{11,12}$

SAMs of $\mathrm{SPh}_{n}$ and $\mathrm{SCH}_{2} \mathrm{Ph}_{n}$ have been characterized extensively. They form structures that are highly-ordered and densely-packed on both silver and gold substrates. ${ }^{22-28}$ (The exception is thiophenol ( $\mathrm{HSPh}$ ) which has been reported to form poorly defined SAMs, possibly due to the weak intermolecular forces between the aromatic rings. ${ }^{22,24,29}$ ) The surface structure of thiolates on metal is the same for SAMs of alkanethiolates and SAMs of aromatics $((\sqrt{3} \mathrm{x}$ $\sqrt{3}) \mathrm{R} 30^{\circ}$ on gold and $(\sqrt{7} \times \sqrt{7}) \mathrm{R} 10.9^{\circ}$ on silver), but the cant angle $(\alpha)$ for the aromatics is slightly less than that of the alkanethiolates $\left(\alpha=\sim 20^{\circ}\right.$ for SAMs of terphenylthiol on Au and $\alpha=\sim 30^{\circ}$ for SAMs of alkanethiols on Au). ${ }^{22,30}$ Oligophenylene groups present in a SAM adopt a near-planar conformation and pack in a herringbone structure. ${ }^{22,31}$

Characterization of SAMs of $\mathrm{C} \equiv \mathrm{CPh}_{\mathrm{n}}$ on gold indicates that the acetylene group binds in an upright configuration on gold. ${ }^{32-34} \mathrm{~A}$ recent report from Zaba and coworkers demonstrates that it is possible to form highly-ordered SAMs of $n$-alkyl acetylenes on gold in non-oxidizing environments; $;{ }^{35}$ the presence of $\mathrm{O}_{2}$ (before or during SAM formation) leads to poorly organized 
films due to oxidation of the acetylene group. (See the supporting information for experimental details on the formation of the SAMs.)

In measurements of charge transport across a Metal-SAM-Metal junction, charges encounter a tunneling barrier whose shape is determined by the electrical characteristics of at least five components: the SAM, the two electrodes, and the two interfaces between the SAM and the electrodes. The Simmons equation ${ }^{18}$ (eq.1) approximately describes the rate of charge transport, assuming a simple rectangular shape for the tunneling barrier. In this approximation, $J(\mathrm{~V})$ decays exponentially with increasing width of the tunneling barrier, $d ; d$ is often taken to be the distance between the two electrodes.

Here, we estimate $d$ by the calculated length of the molecules (in $\AA$, from the anchoring atom to the distal hydrogen atom) making up the SAM. The injection current, $J_{0}(\mathrm{~V})$, is the value of $J(\mathrm{~V})$ expected for a hypothetical junction with $d=0$, but with interfaces characteristic of a SAM-containing junction. According to the Simmons model, the height of the rectangular potential barrier determines the value of the decay factor, $\beta$; for real molecular structures-where the tunneling barrier has a more complicated energetic topography - the relationship between the molecular structure, the shape of the barrier, and the apparent values of $\beta$ and $J_{0}$ has not been defined analytically. For charge transport across SAMs, the electronic structure of the molecules and their orbital energies determine the shape of the tunneling barrier. ${ }^{36}$ Conjugated molecules, which are characterized by the delocalization of orbitals along the molecular backbone, have smaller highest occupied molecular orbital (HOMO)-lowest occupied molecular orbital (LUMO) gaps ( $\sim 3-5 \mathrm{eV}$, Table S7) than saturated $n$-alkanes where the HOMO-LUMO gap is much larger $(\sim 7 \mathrm{eV}) .{ }^{21}$ Moreover, the energy level of the HOMO of conjugated molecules aligns more 
favorably with the Fermi level of the metal, than does that for aliphatic molecules, and results in lower tunneling barriers. ${ }^{16,21,37,38}$

\section{RESULTS AND DISCUSSION}

Table 1 summarizes rates for charge transport using $\mathrm{Ga}_{2} \mathrm{O}_{3} / \mathrm{EGaIn}$ as a top electrode across SAMs of oligophenyls having thiol $(-\mathrm{SH})$ and methanethiol $\left(-\mathrm{CH}_{2} \mathrm{SH}\right)$ anchoring groups on gold and silver substrates, and an acetylene $(-\mathrm{C} \equiv \mathrm{CH})$ anchoring group on gold substrates. We provide a comparison of $\beta$ and $J_{0}$ for standard $n$-alkanethiolates on gold and silver substrates. For all systems, values of $\log |J|$ (Gaussian mean values) varied linearly with $d$. Assuming a throughmolecule transport mechanism, we approximated $d$ as the length of the molecule from the anchoring atom to the distal hydrogen atom. (The diagram in Figure 2 shows this approximation to $d$.) Linear regression analyses of the values of $\log |J|$ versus $d$ yielded the values of the $\log$ injection current $\left(\log \left|J_{0}\right|\right.$, intercept at the $y$ axis) and the tunneling parameter ( $\beta$, slope) for each system (Figure 2).

Charge transport across SAMs of $n$-alkanethiols has been studied extensively by us and others, ${ }^{12,36}$ and the data for these systems on gold and silver $\left(\beta_{A u}=0.76 \pm 0.03 \AA^{-1}\right.$, and $\log \left|J_{0, A u}\right|$ $=4.2 \pm 0.2 ; \beta_{A g}=0.72 \pm 0.05 \AA^{-1}$, and $\left.\log \left|J_{0, A g}\right|=3.6 \pm 0.3\right)$ serve as a reference range against which we correlate trends in electrical behavior with a systematic change in molecular and electronic structure. Measurements of charge tunneling across $\mathrm{SAMs}$ of $\mathrm{SPh}_{\mathrm{n}}$ - with $\mathrm{n}$ increasing from 1 to 3 -yielded $\beta=0.30 \pm 0.02 \AA^{-1}$ on $\mathrm{Ag}^{\mathrm{TS}}$ and $\beta=0.28 \pm 0.03 \AA^{-1}$ on $\mathrm{Au}^{\mathrm{TS}}$ (Figure 2); these values agree with previous experimental reports using single-molecule and large-area junctions. ${ }^{27,38-45}$ These results presented here also agree with theoretical calculations by Ratner and coworkers; these authors predict (using density functional theory, DFT) a value of $\beta=\sim 0.3$ 
$\AA^{-1}$ for SAMs of polyphenyldithiolates by assuming a continuous conjugation of the molecules with the metal electrodes. ${ }^{17}$

We compared the electrical properties of $\mathrm{SAMs}$ of $\mathrm{SPh}_{\mathrm{n}}$ to $\mathrm{SAMs}$ of $\mathrm{C} \equiv \mathrm{CPh}_{\mathrm{n}}$ on $\mathrm{Au}^{\mathrm{TS}}$ (Figure 2b). Both molecular systems are conjugated; that is, the $\pi$-electrons are delocalized across the molecular backbone, but they differ by the chemical structure of the anchoring group (-S- vs. $-\mathrm{C} \equiv \mathrm{C}-$ ). Despite this difference in the anchoring group between the phenyl rings and the metal electrode, the values of $\beta$ for the two SAMs are indistinguishable $\left(\beta=0.28 \pm 0.03 \AA^{-1}\right.$ for $\mathrm{Au} / \mathrm{SPh}_{\mathrm{n}}$ and $\beta=0.30 \pm 0.02 \AA^{-1}$ for $\left.\mathrm{Au} / \mathrm{C} \equiv \mathrm{CPh}_{\mathrm{n}}\right)$.

Electronic structure calculations using density functional theory (DFT) on the series of molecules studied here indicate that the HOMO for both $\mathrm{Au} / \mathrm{SPh}_{\mathrm{n}}$ and $\mathrm{Au} / \mathrm{C} \equiv \mathrm{CPh}_{\mathrm{n}}$ is located (predominately) on the anchoring group and the first two phenyl rings (Table S3 and S4), with the values of the HOMO being comparable for the two molecules $\left(-5.5 \mathrm{eV}\right.$ for $\mathrm{SPh}_{1}$ and $-5.7 \mathrm{eV}$ for $\mathrm{C} \equiv \mathrm{CPh}_{1}$ ). The electronic structure of these conjugated systems differs from saturated $n$ alkanes, where the HOMO is localized on the anchoring atom, with little to no participation by orbitals on the adjacent atoms in the alkyl chain. ${ }^{1}$

Disrupting the delocalization of electron density, from the anchoring groups onto the phenyl rings and the metal substrate, changes the rates of charge transport (Table S5). Specifically, the introduction of an insulating methylene spacer between the sulfur anchoring atom and the first phenyl ring - a modification that generates $\mathrm{SCH}_{2} \mathrm{Ph}_{\mathrm{n}}$, increases the attenuation factor across the molecule to $\beta=0.66 \AA^{-1}$ on $\mathrm{Ag}^{\mathrm{TS}}$ and $\beta=0.66 \AA^{-1}$ on $\mathrm{Au}^{\mathrm{TS}}$ — values close to those $\left(\beta=0.72 \AA^{-1}\right.$ and $\left.\beta=0.76 \AA^{-1}\right)$ for $n$-alkyl thiolates on $\mathrm{Ag}$ and Au. ${ }^{2}$ These values are also similar (within error) to values reported previously for $\mathrm{SAMs}$ of $\mathrm{SCH}_{2} \mathrm{Ph}_{\mathrm{n}} \cdot{ }^{38,46,47}$ The data presented here for oligophenylmethanethiols $\left(\mathrm{SCH}_{2} \mathrm{Ph}_{n}\right)$, as well as our previous measurements 
on oligophenylcarboxylates $\left(\mathrm{O}_{2} \mathrm{CPh}_{\mathrm{n}}\right)$ on silver $\left(\beta=0.60 \AA^{-1}\right),{ }^{11}$ indicate that disrupting the delocalization of electron density from the bottom electrode and the anchoring group to the $\mathrm{Ph}_{\mathrm{n}}$ group results in higher values of $\beta$ than in SAMs of oligophenylthiolates $\left(\mathrm{SPh}_{\mathrm{n}}\right)$. (The presence of an orbital node on the carbon atom of the carboxylate group disrupts the delocalization of orbitals from the $\mathrm{CO}_{2}{ }^{-}$group to the $\mathrm{Ph}_{n}$, and produces an electronic effect similar to the presence of an intervening methylene group.)

The conclusion that tunneling currents through $\mathrm{Ph}_{\mathrm{n}}$ groups are higher than through $n$ alkyls has relied, so far, on the observation that values of $\beta$ for aromatics are generally lower than values of $\beta$ for $n$-alkyls. The value of the injection current, $J_{0}$ - determined by extrapolation of the best fit line to $d=0$-across aromatics has been less discussed than that for $\beta$, due in substantial part to differences in the reported values of $J_{0}$ (even for standard $n$-alkanethiolates) across techniques. Here we compare values of $J_{0}$ obtained using a single technique.

The value of $J_{0}$ is indistinguishable for $\mathrm{SAMs}$ of $\mathrm{SCH}_{2} \mathrm{Ph}_{\mathrm{n}}$ and $\mathrm{S}\left(\mathbf{C H}_{2}\right)_{\mathrm{n}} \mathrm{CH}_{3}$ on both silver $\left(\log \left|J_{0}\right|=3.7 \pm 0.3\right.$ for $\mathbf{S C H}_{2} \mathrm{Ph}_{\mathrm{n}}$ and $3.6 \pm 0.3$ for $\left.\mathbf{S}\left(\mathbf{C H}_{2}\right)_{n} \mathrm{CH}_{3}\right)$ and gold $\left(\log \left|J_{0}\right|=4.0 \pm\right.$ 0.2 for $\mathbf{S C H}_{2} \mathrm{Ph}_{\mathrm{n}}$ and $4.2 \pm 0.2$ for $\left.\mathrm{S}\left(\mathbf{C H}_{2}\right)_{n} \mathrm{CH}_{3}\right)$. Frisbie and coworkers made a similar observation using CP-AFM. ${ }^{47}$ They reported the same contact resistance $\left(R_{0}\right)$ for SAMs of oligophenylmethanethiols and SAMs of $n$-alkanethiols on gold. One possible explanation for the similar values of $J_{0}$ is the similarity in the interface between the SAM and the bottom electrode: both SAMs have a metal/SCH $\mathbf{S}_{2}$ - interface. SAMs of oligophenyls that lack a methylene spacer, here $\mathrm{SPh}_{\mathrm{n}}$ (on gold and silver) and $\mathrm{C} \equiv \mathrm{CPh}_{\mathrm{n}}$ (on gold), give values of $J_{0}$ that are lower by about a factor of 10 than $J_{0}$ observed for $n$-alkanethiolates $\left(\log \left|J_{0}\right|=4.2 \pm 0.2\right.$; Figure 2). 


\section{CONCLUSIONS}

This study reports—using EGaIn top electrodes—values of $\beta$ and $J_{0}$ for three series of aromatic $\mathrm{SAMs}\left(\mathrm{SPh}_{\mathrm{n}}, \mathrm{SCH}_{2} \mathrm{Ph}_{\mathrm{n}}\right.$, and $\mathrm{C} \equiv \mathrm{CCH}_{2} \mathrm{Ph}_{\mathrm{n}}$ on gold and silver substrates). These results demonstrate a remarkable and (to us) unexpected sensitivity of the tunneling current through these junctions to the structure of the interface between the metal (Au or Ag) bottom electrode and the SAM. This sensitivity is clear from a comparison of two observations. i) The value of $\beta$ is indistinguishable for $\mathrm{SPh}_{\mathrm{n}}$ and $\mathrm{C} \equiv \mathrm{CPh}_{\mathrm{n}}$ on gold — two series of SAMs that differ substantially in the structure of the anchoring group. ii) The introduction of a single $\mathrm{CH}_{2}$ group between the aromatic group and the sulfur anchoring atom-generating $\mathrm{SCH}_{2} \mathrm{Ph}_{n}-$ increases the attenuation in tunneling current with distance $(\beta)$ to a value very similar to that of a length-matched saturated aliphatic SAM. That is, the contribution of the $\mathrm{Ph}_{n}$ unit to the rate of tunneling essentially disappears. The introduction of the $\mathrm{CH}_{2}$ group between the Metal-S unit and the $\mathrm{Ph}_{n}$ group plausibly interrupts the delocalization of orbitals on the HOMO from the $\mathrm{S}$ to the $\mathrm{Ph}_{\mathrm{n}}$, but a theoretical rationalization of this change on the tunneling rates will depend on detailed calculations.

The measurement and interpretation of the parameter $J_{0}$ in the simplified Simmons equation (eq. 1) are both complicated. We list here some of the issues which make this empirical parameter simply that, until a theory develops to the point where it can be better correlated with specific experimental tests.

i) The Validity of the Simmons Equation. The simplified Simmons equation is, in fact, simplified, and the rectangular tunneling barrier, which the complete Simmons equation describes, is itself an approximation (of undefined validity) to a description of the tunneling barrier experienced by charge in SAM-based tunneling junctions. The apparent importance of the 
interfaces between the SAM and the two electrodes is particularly interesting (and perhaps problematic).

ii) Interfacial Effects: Differences in the Strength of the Interaction of the SAM with the Metal. In our experimental system, it is possible that the observation of a lower value of $J_{0}$ for Metal/S-Ph $\mathbf{n}$ than for Metal/S- $\mathbf{C H}_{\mathbf{2}} \mathbf{P} \mathbf{h}_{\mathbf{n}}$ might reflect difference in the strength of the interaction at the Metal/SAM interface, perhaps, in turn, reflecting a difference in the pKa values $(\sim 8$ for $\mathrm{HSPh}$ and $\sim 10$ for $\mathrm{HSCH}_{2} \mathrm{Ph}$ ) of the thiols. We consider this possibility to be unlikely given the comparison of $J_{0}$ with $\mathrm{Au} / \mathrm{C} \equiv \mathrm{CPh}_{\mathrm{n}}$. The acetylene moiety $(\mathrm{H}) \mathrm{C} \equiv \mathrm{CPh}_{\mathrm{n}}$ has both a higher $\mathrm{pKa}$ ( 19) and a higher binding strength to $\mathrm{Au}$ than either $\mathrm{SPh}$ and $\mathrm{SCH}_{2} \mathrm{Ph}(\sim 70 \mathrm{kcal} / \mathrm{mol}$ for $\mathrm{Au}-\mathrm{C}$ and $\sim 30 \mathrm{kcal} / \mathrm{mol}$ for $\mathrm{Au}-\mathrm{S})$, yet the $\log \left|J_{0}\right|$ of $\mathrm{C} \equiv \mathrm{CPh}_{\mathrm{n}}$ and $\mathrm{SPh}$ are similar $(3.0 \pm 0.1$ and $2.7 \pm$ $0.1)$.

iii) Interfacial Effects: Differences in the Fermi Level of the Metal. The introduction of a single $\mathrm{CH}_{2}$ group between the anchoring group and the first phenyl ring (in the case of Metal/S$\mathrm{CH}_{2} \mathrm{Ph}_{\mathrm{n}}$ ) could modify the Fermi level of the metal, compared to Metal/S- $\mathrm{Ph}_{\mathrm{n}}$, and result in dissimilarities in the injection current

iv) Differences in the Molecular Arrangement of the SAM. STM measurements by Tokumoto and coworkers on $\mathrm{Au} / \mathrm{S}-\mathbf{C H}_{2} \mathbf{P h}$ indicate highly-ordered commensurate $(\sqrt{ } 3 \times \sqrt{ } 3)$ $\mathrm{R} 30^{\circ}$ structures; the absence of the methylene spacer makes it more difficult to obtain highlyordered structures. ${ }^{29}$ It is possible that the differences in order and packing density could lead to error in the estimation of $J_{0}$.

v) Error Associated with the Extrapolation of the Best Fit Line to Determine $J_{0}$. The determination of $J_{0}$ for most compounds, with the exception of $n$-alkylthiolates, has been carried out as an estimation of the thickness of the SAM and extrapolating to $d=0$. Because it has been 
possible to make SAMs of $n$-alkanethiolates on gold with lengths ranging from $\mathrm{C} 1$ to $\mathrm{C} 18$, this estimation has seemed to work well for comparing the values of $J_{0}$ for SAMs having welldefined alkyl groups. Relying on this method of estimation, however, may no longer be valid for the $\mathrm{Ph}_{\mathrm{n}}$-based molecules studied here, or for other systems where the molecules in the SAM have structures that are less homogenous than are the $n$-alkanes. Estimations based on extrapolations require (perhaps incorrectly) the assumption that $\beta$ is uniform along the entire length of the molecule being examined.

The introduction of a methylene spacer between the phenyl group and the anchoring atom also influences the value of the injection current; that is, the $J_{0}$ is higher for SAMs with a methylene spacer than for those without one. These differences in $J_{0}$ for Metal/S-Ph and Metal/S- $\mathbf{C H}_{\mathbf{2}} \mathbf{P h}$ are, however, more ambiguous in their interpretation than are values of $\beta$. The parameter " $J_{0}$ " in the simplified Simmons equation is often interpreted to be the current through a hypothetical junction with $d=0$, but having interfacial characteristics the same as when there is a SAM present. $J_{0}$ is, however, subject to both uncertainties in meaning and in experimental interpretation (which we summarize briefly in the supporting information); here we note only that in the systems described here (and also in other systems we have studied), ${ }^{5}$ a decrease in $\beta$ is often accompanied by a decrease in $J_{0}$.

In addition to characterizing the values of $\beta$ and $J_{0}$ across a series of structurally distinct oligophenyls using EGaIn as the top electrode, this study highlights some important features of the tunneling barrier that went undetected in earlier studies using insulating alkanes with a localized HOMO on the anchoring group. Our previous investigations on the influence of the Metal/SAM interface on rates of charge transport considered alkyl-based SAMs having different anchoring groups (e.g., $\mathrm{S}, \mathrm{C} \equiv \mathrm{C}$, and $\left.\mathrm{O}_{2} \mathrm{C}\right) .{ }^{11,48}$ This study suggested-based on indistinguishable 
values of $\beta$ and $J_{0}$ - that the interface between the metal and the SAM was not important in determining rates of charge transport. The current study analyzes conjugated molecular systems where the HOMO extends beyond the anchoring group and onto the phenyl rings. Changes to the interface that cause a disruption in the delocalization of the HOMO appear to raise the height of the barrier at the interface, inducing an increase in $\beta$. The interesting trend that is emerging from these and related studies ${ }^{5,48}$ is that the introduction of groups that decreases the strength of the interactions, and thus increases the height of the barrier, at either interface increases $\beta$ and increases $J_{0}$.

\section{ASSOCIATED CONTENT}

\section{Supporting Information}

Detailed experimental procedure, histograms of current densities, and summary of junction measurements. This material is available free of charge via the Internet at http://pubs.acs.org.

\section{AUTHOR INFORMATION}

\section{Corresponding Author}

*gwhitesides@gmwgroup.harvard.edu

\section{Notes}

The authors declare no competing financial interest.

\section{ACKNOWLEDGEMENT}

This work was supported by a subcontract from Northwestern University from the United States Department of Energy (DOE, DE-SC0000989) and by the National Science Centre Poland (grant DEC-2013/10/E/ST5/00060). The DOE grant from Northwestern also supported the salary for C.M.B, M.B., F.C.S, and K.-C.L. The Cyberdiscovery Initiative Type II (CDI2) grant from the 
National Science Foundation (NSF, OIA-1125087) supported the salary for D.R. Sample characterization was performed at the Center for Nanoscale Systems (CNS) at Harvard University, a member of the National Nanotechnology Infrastructure Network (NNIN), which is supported by the National Science Foundation (ECS-0335765). This work was also partially funded by NSF award CHE-1506993. In particular, we appreciate the assistance of Dr. Hao-Yu Lin at CNS. We thank Dr. Benjamin Breiten for his assistance in the synthesis of terphenylacetylene. 

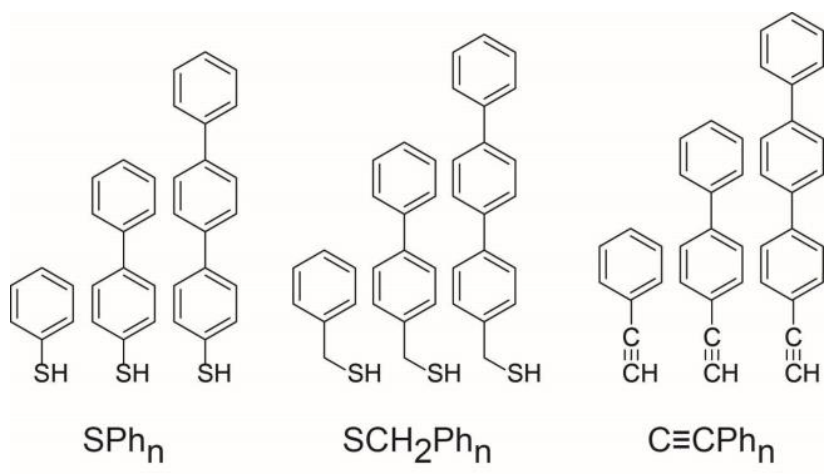

Figure 1. Structure of oligophenylthiols $(-\mathrm{SH})$, -methanethiols $\left(-\mathrm{CH}_{2} \mathrm{SH}\right)$, and -acetylenes ($\mathrm{C} \equiv \mathrm{CH}$ ) used to form $\mathrm{SAMs}$ on $\mathrm{Ag}^{\mathrm{TS}}$ and $\mathrm{Au}^{\mathrm{TS}}$. ("Ph" indicates a phenylene ring; $\mathrm{n}=$ number of $\mathrm{Ph}$.) For each molecule, we measured the length $d$ of the tunneling barrier as the distance from the anchoring atom (sulfur or carbon directly coordinated to the metal substrate) to the distal Hatom of each molecule. 
Table 1. Summary of the parameters of the Simmons equation (eq. 1) describing rates of charge transport across SAMs of oligophenylthiols $(-\mathrm{SH})$, -methanethiols $\left(-\mathrm{CH}_{2} \mathrm{SH}\right)$, and -acetylenes ($\mathrm{C} \equiv \mathrm{CH})$ at $\mathrm{V}=+0.5 \mathrm{~V}$.

\begin{tabular}{lcccc}
\hline $\begin{array}{l}\text { Bottom } \\
\text { Metal } \\
\text { Electrode }\end{array}$ & $\begin{array}{c}\text { Anchoring } \\
\text { Atom/Group }\end{array}$ & SAM & $\begin{array}{c}\mathbf{L o g}\left|\boldsymbol{J}_{\mathbf{0}}\right|^{\mathbf{a}} \\
\mathbf{V = + + 0 . 5 ~ V}\end{array}$ & $\boldsymbol{\beta}\left(\AA^{-\mathbf{1}}\right)^{\mathbf{b}}$ \\
\hline $\mathrm{Ag}$ & $-\mathrm{S}-$ & $-\mathrm{Ph}_{\mathrm{n}} \mathrm{H}$ & $2.9 \pm 0.1$ & $0.30 \pm 0.02$ \\
$\mathrm{Ag}$ & $-\mathrm{CH}_{2} \mathrm{~S}-$ & $-\mathrm{Ph}_{\mathrm{n}} \mathrm{H}$ & $3.7 \pm 0.3$ & $0.66 \pm 0.06$ \\
$\mathrm{Ag}$ & $-\mathrm{S}-$ & $-\left(\mathrm{CH}_{2}\right)_{\mathrm{n}} \mathrm{CH}_{3}$ & $3.6 \pm 0.3$ & $0.72 \pm 0.05$ \\
\hline $\mathrm{Au}$ & $-\mathrm{S}-$ & $-\mathrm{Ph}_{\mathrm{n}} \mathrm{H}$ & $2.7 \pm 0.1$ & $0.28 \pm 0.03$ \\
$\mathrm{Au}$ & $-\mathrm{CH}_{2} \mathrm{~S}-$ & $-\mathrm{Ph}_{\mathrm{n}} \mathrm{H}$ & $4.0 \pm 0.3$ & $0.66 \pm 0.06$ \\
$\mathrm{Au}$ & $-\mathrm{C} \equiv \mathrm{C}-$ & $-\mathrm{Ph}_{\mathrm{n}} \mathrm{H}$ & $3.0 \pm 0.1$ & $0.30 \pm 0.02$ \\
$\mathrm{Au}$ & $-\mathrm{S}-$ & $-\left(\mathrm{CH}_{2}\right)_{\mathrm{n}} \mathrm{CH}_{3}$ & $4.2 \pm 0.2$ & $0.76 \pm 0.03$ \\
\hline
\end{tabular}

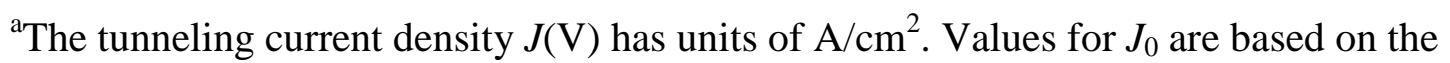
extrapolation of the best fit linear regression line to $y=0$, a direct comparison of these values may not be accurate due to the uncertainty of current density values in the zero-length regime.

${ }^{b}$ The values of $d(\AA)$ used to calculate $\beta$ are determined from the anchoring atom directly bound to bottom metal electrode to the distal hydrogen atom in van der Waals contact with $\mathrm{Ga}_{2} \mathrm{O}_{3} / \mathrm{EGaIn}$. 
a)
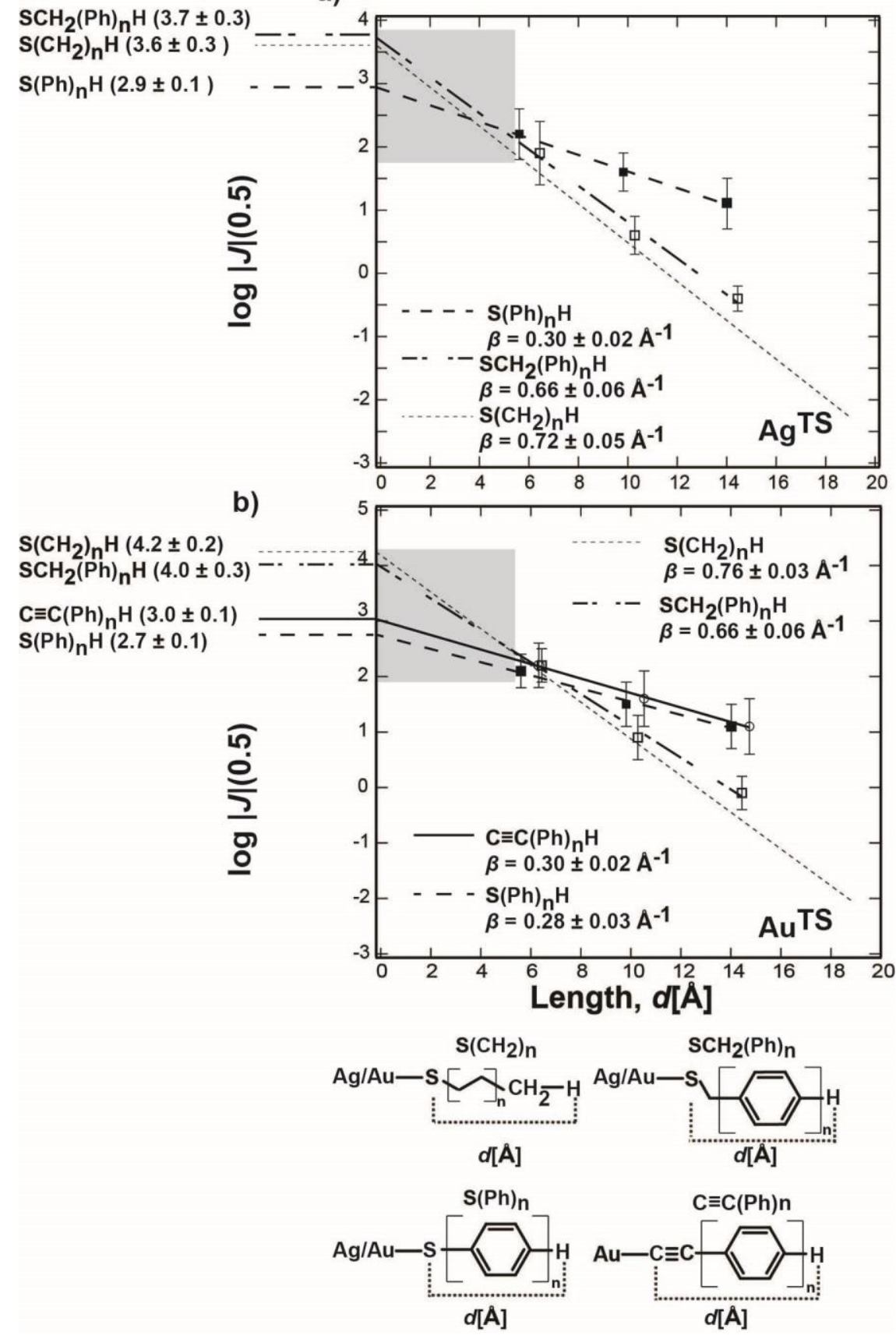

Figure 2. Plots of the Gaussian mean values of $\log |J|$ at $+0.5 \mathrm{~V}$ versus molecular length for aromatic SAMs on a) $\mathbf{A g}^{\mathbf{T S}}$ and b) $\mathbf{A u}{ }^{\mathbf{T S}}$. The distance (dotted line) is calculated from the anchoring atom, which binds covalently to the bottom electrode, to the distal hydrogen atom that in van der Waals contact with the $\mathrm{Ga}_{2} \mathrm{O}_{3} / \mathrm{EGaIn}$ electrode, by assuming an all trans-extended conformation for $n$-alkanethiolates. The grey box indicates the region over which data must be extrapolated to estimate $J_{0}(\mathrm{~V})$ at $d=0$. Since the structural elements in this region differ from those in the region where there are data (the region of $\mathrm{Ph}_{\mathrm{n}}$ ) extrapolation may be inappropriate for $\mathrm{S}(\mathrm{Ph})_{\mathrm{n}}$ and $\mathrm{C} \equiv \mathrm{C}(\mathrm{Ph})_{\mathrm{n}}$, although the correction of this extrapolation is well-validated for $n$ alkanethiolates on gold and silver. ${ }^{2,12}$ 


\section{REFERENCES}

(1) Mirjani, F.; Thijssen, J. M.; Whitesides, G. M.; Ratner, M. A. ACS Nano 2014, 8, 1242812436.

(2) Baghbanzadeh, M.; Simeone, F. C.; Bowers, C. M.; Liao, K.-C.; Thuo, M.; Baghbanzadeh, M.; Miller, M. S.; Carmichael, T. B.; Whitesides, G. M. J. Am. Chem. Soc. 2014, 136, 1691916925.

(3) Toledano, T.; Sazan, H.; Mukhopadhyay, S.; Alon, H.; Lerman, K.; Bendikov, T.; Major, D.

T.; Sukenik, C. N.; Vilan, A.; Cahen, D. Langmuir 2014, 30, 13596-13605.

(4) Thuo, M. M.; Reus, W. F.; Nijhuis, C. A.; Barber, J. R.; Kim, C.; Schulz, M. D.; Whitesides, G. M. J. Am. Chem. Soc. 2011, 133, 2962-2975.

(5) Liao, K.-C.; Bowers, C. M.; Yoon, H. J.; Whitesides, G. M. Submitted for publication.

(6) Nerngchamnong, N.; Yuan, L.; Qi, D. C.; Li, J.; Thompson, D.; Nijhuis, C. A. Nat.

Nanotehnol. 2013, 8, 113-118.

(7) Nijhuis, C. A.; Reus, W. F.; Siegel, A. C.; Whitesides, G. M. J. Am. Chem. Soc. 2011, 133, 15397-15411.

(8) Nijhuis, C. A.; Reus, W. F.; Whitesides, G. M. J. Am. Chem. Soc. 2010, 132, 18386-18401.

(9) Yoon, H. J.; Liao, K.-C.; Lockett, M. R.; Kwok, S. W.; Baghbanzadeh, M.; Whitesides, G.

M. J. Am. Chem. Soc. 2014, 136, 17155-17162.

(10) Bowers, C. M.; Liao, K.-C.; Yoon, H. J.; Rappoport, D.; Baghbanzadeh, M.; Simeone, F.

C.; Whitesides, G. M. Nano Lett. 2014, 14, 3521-3526.

(11) Liao, K.-C.; Yoon, H. J.; Bowers, C. M.; Simeone, F. C.; Whitesides, G. M. Angew. Chem. Int. Ed. 2014, 53, 3889-3893.

(12) Simeone, F. C.; Yoon, H. J.; Thuo, M. M.; Barber, J. R.; Smith, B.; Whitesides, G. M. J. Am. Chem. Soc. 2013, 135, 18131-18144.

(13) Thuo, M. M.; Reus, W. F.; Simeone, F. C.; Kim, C.; Schulz, M. D.; Yoon, H. J.; Whitesides, G. M. J. Am. Chem. Soc. 2012, 134, 10876-10884.

(14) Yoon, H. J.; Bowers, C. M.; Baghbanzadeh, M.; Whitesides, G. M. J. Am. Chem. Soc. 2014, 136, 16-19.

(15) Yoon, H. J.; Shapiro, N. D.; Park, K. M.; Thuo, M. M.; Soh, S.; Whitesides, G. M. Angew. Chem. Int. Ed. 2012, 51, 4658-4661.

(16) Wu, S. M.; Gonzalez, M. T.; Huber, R.; Grunder, S.; Mayor, M.; Schonenberger, C.;

Calame, M. Nat. Nanotechnol. 2008, 3, 569-574.

(17) Cohen, R.; Stokbro, K.; Martin, J. M. L.; Ratner, M. A. J. Phys. Chem. C 2007, 111, 1489314902.

(18) Simmons, J. G. J. Appl. Phys. 1963, 34, 1793-1803.

(19) Heimel, G.; Rissner, F.; Zojer, E. Adv. Mater. 2010, 22, 2494-2513.

(20) Heimel, G.; Romaner, L.; Bredas, J. L.; Zojer, E. Langmuir 2008, 24, 474-482.

(21) Kong, L. M.; Chesneau, F.; Zhang, Z. Z.; Staier, F.; Terfort, A.; Dowben, P. A.; Zharnikov, M. J. Phys. Chem. C 2011, 115, 22422-22428.

(22) Frey, S.; Stadler, V.; Heister, K.; Eck, W.; Zharnikov, M.; Grunze, M.; Zeysing, B.; Terfort, A. Langmuir 2001, 17, 2408-2415.

(23) Duan, L.; Garrett, S. J. J. Phys. Chem. B 2001, 105, 9812-9816.

(24) Ishida, T.; Mizutani, W.; Azehara, H.; Miyake, K.; Aya, Y.; Sasaki, S.; Tokumoto, H. Surf.

Sci. 2002, 514, 187-193. 
(25) de Boer, B.; Meng, H.; Perepichka, D. F.; Zheng, J.; Frank, M. M.; Chabal, Y. J.; Bao, Z. N. Langmuir 2003, 19, 4272-4284.

(26) Tour, J. M.; Jones, L.; Pearson, D. L.; Lamba, J. J. S.; Burgin, T. P.; Whitesides, G. M.; Allara, D. L.; Parikh, A. N.; Atre, S. V. J. Am. Chem. Soc. 1995, 117, 9529-9534.

(27) Kronemeijer, A. J.; Huisman, E. H.; Akkerman, H. B.; Goossens, A. M.; Katsouras, I.; van Hal, P. A.; Geuns, T. C. T.; van der Molen, S. J.; Blom, P. W. M.; de Leeuw, D. M. Appl. Phys. Lett. 2010, 97, 173302.

(28) Shaporenko, A.; Elbing, M.; Baszczyk, A.; von Hanisch, C.; Mayor, M.; Zharnikov, M. J. Phys. Chem. B 2006, 110, 4307-4317.

(29) Ishida, T.; Mizutani, W.; Choi, N.; Akiba, U.; Fujihira, M.; Tokumoto, H. J. Phys. Chem. B 2000, 104, 11680-11688.

(30) Love, J. C.; Estroff, L. A.; Kriebel, J. K.; Nuzzo, R. G.; Whitesides, G. M. Chem. Rev. 2005, 105, 1103-1169.

(31) Heister, K.; Zharnikov, M.; Grunze, M.; Johansson, L. S. O. J. Phys. Chem. B 2001, 105, 4058-4061.

(32) Maity, P.; Takano, S.; Yamazoe, S.; Wakabayashi, T.; Tsukuda, T. J. Am. Chem. Soc. 2013, $135,9450-9457$.

(33) Ford, M. J.; Hoft, R. C.; McDonagh, A. J. Phys. Chem. B 2005, 109, 20387-20392.

(34) McDonagh, A. M.; Zareie, H. M.; Ford, M. J.; Barton, C. S.; Ginic-Markovic, M.; Matisons, J. G. J. Am. Chem. Soc. 2007, 129, 3533-3538.

(35) Zaba, T.; Noworolska, A.; Bowers, C. M.; Breiten, B.; Whitesides, G. M.; Cyganik, P. J. Am. Chem. Soc. 2014, 136, 11918-11921.

(36) Engelkes, V. B.; Beebe, J. M.; Frisbie, C. D. J. Am. Chem. Soc. 2004, 126, 14287-14296.

(37) Beebe, J. M.; Kim, B.; Frisbie, C. D.; Kushmerick, J. G. ACS Nano 2008, 2, 827-832.

(38) Holmlin, R. E.; Haag, R.; Chabinyc, M. L.; Ismagilov, R. F.; Cohen, A. E.; Terfort, A.;

Rampi, M. A.; Whitesides, G. M. J. Am. Chem. Soc. 2001, 123, 5075-5085.

(39) Anariba, F.; McCreery, R. L. J. Phys. Chem. B 2002, 106, 10355-10362.

(40) Kaliginedi, V.; Moreno-Garcia, P.; Valkenier, H.; Hong, W.; Garcia-Suarez, V. M.; Buiter, P.; Otten, J. L.; Hummelen, J. C.; Lambert, C. J.; Wandlowski, T. J. Am. Chem. Soc. 2012, 134, 5262-5275.

(41) Peng, G.; Strange, M.; Thygesen, K. S.; Mavrikakis, M. J. Phys. Chem. C 2009, 113, 2096720973.

(42) Quek, S. Y.; Choi, H. J.; Louie, S. G.; Neaton, J. B. Nano Lett. 2009, 9, 3949-3953.

(43) Holmlin, R. E.; Ismagilov, R. F.; Haag, R.; Mujica, V.; Ratner, M. A.; Rampi, M. A.;

Whitesides, G. M. Angew. Chem. Int. Ed. 2001, 40, 2316-2320.

(44) Querebillo, C. J.; Terfort, A.; Allara, D. L.; Zharnikov, M. J. Phys. Chem. C 2013, 117, 25556-25561.

(45) Masillamani, A. M.; Crivillers, N.; Orgiu, E.; Rotzler, J.; Bossert, D.; Thippeswamy, R.; Zharnikov, M.; Mayor, M.; Samori, P. Chem. Eur. J. 2012, 18, 10335-10347.

(46) Fracasso, D.; Muglali, M. I.; Rohwerder, M.; Terfort, A.; Chiechi, R. C. J. Phys. Chem. C 2013, 117, 11367-11376.

(47) Wold, D. J.; Haag, R.; Rampi, M. A.; Frisbie, C. D. J. Phys. Chem. B 2002, 106, 2813-2816.

(48) Bowers, C. M., Liao, K.C., Zaba, T., Rappoport, D., Baghbanzadeh, M., Breiten, B.,

Cyganik, P., Whitesides, G.M. ACS Nano 2015, DOI: 10.1021/nn5059216. 